\title{
Pronunciation Obstacle Course
}

\author{
Igor Ivanović \\ Faculty of Philology, University of Montenegro, Nikšić, Montenegro
}

\begin{abstract}
Form our experience as a university professor, many language classrooms are not attentive to pronunciation and it is often neglected. The two major factors contributing to this situation are teachers' inability to teach their students proper pronunciation (pronunciation does not exist in or is a minor part of school curricula or teachers themselves are unable to produce native or native-like pronunciation) and the linguistic barrier posed by the native language. For instance, students sometimes feel great discomfort if they have to express themselves in a foreign language. In case of Montenegro, certain English phonemes such as / $\theta /$, classified as a voiceless dental fricative and $/ \delta /$, classified as a voiced dental fricative, when used in our language, represent the way a person with a speech sound disorder would speak. On the more positive note, our students, more and more, travel to different countries, which improves their ability to speak a foreign language fluently and attain a native-like accent. In this paper, we will deal with certain misconceptions about pronunciation and then our attention will turn to elements affecting the way pronunciation is learnt. Towards the end of our paper, we will consider what language learners need in terms of improving their pronunciation. This is of vital importance since pronunciation may be a great contributing factor, leading to an improved $\mathrm{L} 2$ perception.
\end{abstract}

Index Terms - pronunciation, prosody, intonation, rhythm, language learning

\section{INTRODUCTION}

There seems to be consensus that those who start learning languages later on, for instance, after the end of their formal education, are more likely to have more challenges in terms of acquiring native-like or even satisfactory or intelligible pronunciation and this degree of difficulty increases significantly with age. This gradual decline in the ability to have satisfactory pronunciation is related to numerous factors and it is very difficult to pinpoint which factor is dominant in terms of one's command of foreign language vocabulary, pronunciation and grammar. Since we have no universal answer to the question of why pronunciation may be such an arduous goal to achieve, there are numerous theoretical perspectives trying to tackle the issue. Phonologists, sociolinguists and psycholinguists specialised in the area, generally subscribe to the notion that trying to learn to pronounce words of a foreign language is more of cognitive nature, which means pronunciation is linked to the conceptualisation and mental classification of "raw sounds". Depending on the level they aspire to attain, many L2 learners have "major pronunciation-related difficulties" even after spending several years honing their pronunciation. The consequence of this can be facing difficulties when trying to find employment. Hinofotis and Baily (Hinofotis \& Baily, 1980) stated, "up to a certain proficiency standard, the fault which most severely impairs the communication process in EFL/ESL learners is pronunciation". This is also true for vocabulary and/or grammar, but the obstacle called "satisfactory pronunciation" can prove to be a more daunting task. Davis (Davis, 1999), for example, reveals that pronunciation is the main concern and one of the ultimate priorities of ESL learners after completing elementary and intermediate courses in English. Now, it is important make a distinction between pronunciation and speaking. Pronunciation is understood as a sub-skill of speaking and if we want to change the way a learner pronounces words, we need to change the way they conceptualise the component sounds of those words. This is true not just for individual sounds, but for higher structures of speech, such as stress patterns, rhythm and syllables. However, the teaching of pronunciation remains largely neglected in the field of foreign language teaching. In our paper, we will be discussing about some relatively frequent misconceptions about pronunciation and the factors affecting the learning of pronunciation. At the end of the paper, we will turn our attention to the needs of learners and offer some suggestions for teaching pronunciation.

\section{KEEP YOUR EYE ON THE BALL}

Quite often, pronunciation skills are equated with musical skills in the sense that people with "a good ear for music" are somehow predestined to have good pronunciation. However, no definitive link between one's capability to reproduce music and accurately reproduce native or native-like pronunciation has ever been established. Moreover, there is a multitude of people who have one of these talents, but not both. Moreover, language pronunciation as a cognitive skill may be closer to some people, meaning some people show natural tendency and aptitude to learn pronunciation to a certain degree, if given adequate opportunity. One of the main problems is that L2 learners need to change their conceptual pattern internalised in childhood and already heavily utilised for their first language. Another challenge is that learners categorise and conceptualise sounds in a way that is not appropriate for a foreign language. Thus, if a learner simply sees a sound articulation diagram, no matter how "interactive" and how accurate, this will not 
help them, unless they are given assistance in terms of understanding what properties of the sound in question are important and offered correct ways of mentally visualising the sound so that they are able to reproduce it. This is why it is difficult for majority of learners and professors as well to make the connexion between a speech wave and the sound auditory quality. In the same vein, detailed knowledge about the way one should coordinate the movement of his legs and hands will not necessarily help an aspiring volleyball player perfect his or her game. Similarly, as far as a tennis player is concerned, what helps is to contemplate about the actions, e.g. "keep your eye on the ball" and "think about hitting from the baseline", (Baker, 1981). Taking into consideration the fact that people generally think about auditory quality of sounds, rather than sound articulation or acoustics, one of the main tasks of professors or instructors is to describe sound auditory quality in a manner that is logical to a language learner. This is the place where computers can enter the stage and help learners with pronunciation and display speech-waves with instructions as to how to read and understand different sounds. Understanding is of vital importance since the statement that the learners acquire an accent chiefly because they "transfer" the sound system of their native language to L2 is only partially true. This notion of transfer, which "models" somebody's accent is valid, but only if used in an elaborated form that requires a good grasp of its ramifications and limitations. A simplified idea that learners just transfer the sound system of their native languages to a new language does not help.

Foreign accent does not just equate to an inability of a speaker of another language to produce L2 sounds. Truth to be told, there are individual as well as groups of sounds that are very difficult in terms of their reproduction for learners from different countries, cultures and social backgrounds. However, we must not forget that this kind of difficulty is not the main cause of the accent and it is a relatively minor aspect of intelligibility. This is the case since individual sounds are not of vital importance to intelligibility. As we know, native speakers' reproduction of particular sounds (especially vowels) differ depending on their accent, region, social background, etc. This is why a learner with proper intonation and unsatisfactory reproduction of, say, "ing - //n/, / $/ \mathrm{n} /$, /ən/”, is generally easy to understand. It is interesting to notice that if a learner does not satisfactorily pronounce an L2 sound, they are, nevertheless, able to pronounce an acceptable version of a similar sound in his/her mother tongue or within another context. A good example of this would be the problem my students who learn Montenegrin as their second language have with the "č" and "dž" sounds, which are very similar to the English affricates, the "ch sound $/ \mathrm{t} /$ " and " $\mathrm{j}$ sound $/ \mathrm{dz} /$ ". Thus, here we cannot talk about learners" inability to produce these sounds. Quite the contrary, almost invariably, learners are able to produce quite acceptable versions of all of the abovementioned sounds. The problem lies in the fact that these learners do not think of these sounds as individual sounds, stored in different "mental drawers", but rather think of them as almost identical variants of the same sound. Another example of this would be the pronunciation of English words such as "plan", "burn" and "ticket", with which Japanese people often have a lot of difficulty. Majority of our students from Japan would pronounce them as “/præn/", "/bə:ln/" and "/'t $\int \mathrm{IkIt} /$ " and the challenge lies in the perception of the acoustic differences of $/ 1 /$ and $/ \mathrm{r} /$. On that note, Spanish learners of English, in terms of speaking and comprehension, may have problems differentiating long and short vowel sounds such as "not", "note" and "nought". Since these three words contain vowels of different length, realised with different mouth positions, it may be useful for the teachers to thoroughly explain their students the concepts of vowel length and production place. This can be done by linking the mechanics and logic of vowel production in Spanish and English, so the students are able to comprehend, visualise and "switch" from one sound system to another.

\section{Pronunciation Challenges}

The following section will elaborate on different factors affecting the learning of pronunciation.

\section{A. Accent}

Empirical evidence to date suggests that the timing of the first genuine and significant exposure to the foreign language deeply affect the "nativeness" of pronunciation and are usually viewed as the best predictors. We must not forget language aptitude, affective aspects and the quality and quantity of input. Simply put, an accent is "the cumulative auditory effect of those features of pronunciation that identify where a person is from, regionally or socially" (Crystal, 2003). Accentedness, a "normal consequence of second language learning" (Zielinski, 2012), is a "listener's perception of how different a speaker's accent is from that of the L1 community" (p. 85). Eric Lenneberg (Lenneberg, 1967) advanced the critical period hypothesis that states that there is a critical time for language acquisition and puberty is the period when brain functions become fully assigned to specific portions of the brain and the brain loses its plasticity. This language-learning window of opportunity closes around the age of twelve. The closure of the critical period signals that the innate language ability responsible for language development is lost and cannot be recovered. Pursuant to the fundamental difference hypothesis (Bley-Vroman, 1989), as opposed to young learners who use universal grammar, late learners rely on their native language knowledge that prevents them from ever achieving the mastery of foreign language pronunciation at a native-speaker level.

\section{B. Intonation as Suprasegmental Melody and Rhythm and Stress as Suprasegmental Stress Patterns}

Munro and Derwing (Derwing \& Munro, Second language accent and pronunciation teaching: A research-based approach., 2005) noted that even heavily accented speech is, in the majority of cases, intelligible and that prosodic 
errors (intonation, rhythm and stress) seem to impact intelligibility more than phonetic errors (single sound errors). Due to this fact, pronunciation teaching have to focus both on the sounds of language (consonant and vowels) and on suprasegmental features or vocal elements encompassing more than one sound. These elements are word and sentence intonation, stress and speech rhythm (Low, 2006). This is further supported by the fact that languages have been classified as either stress-timed or syllable-timed, although this classification is, by no means, exhaustive. In stress-timed languages (e.g., English, Dutch, German, etc.), "stressed syllables fall at regular intervals throughout an utterance" (Crystal, 2003), and rhythm is organised according to the stressed syllables timing regularity. That is, because unstressed syllables are spoken more quickly and vowel reduction occurs, the time between stressed syllables is equal.

As we have pointed out in the text above, languages cannot be strictly classified as syllable-timed or stress-timed. A more accurate description is that languages are stress-based or syllable-based, that is, they tend to cover more than one category, but "want" to have more stress-timed or syllable-timed features (Low, 2006). Stress-based rhythm, which serves as the liaison for other phonological structures (assimilation, deletion, etc.) is achieved through the presence of reduced vowels for unstressed syllables. The best example of this is function words (e.g., articles, auxiliary and modal verbs, prepositions) which usually have reduced vowels instead of full ones, and this reduced vowel form is known as a weak form. For example, in the sentence "I thought it was nice," the words thought and nice carry the main stress, and was, which is unstressed, may be pronounced as [wəz], as its weak form, which is reflected in the following pitch recording:

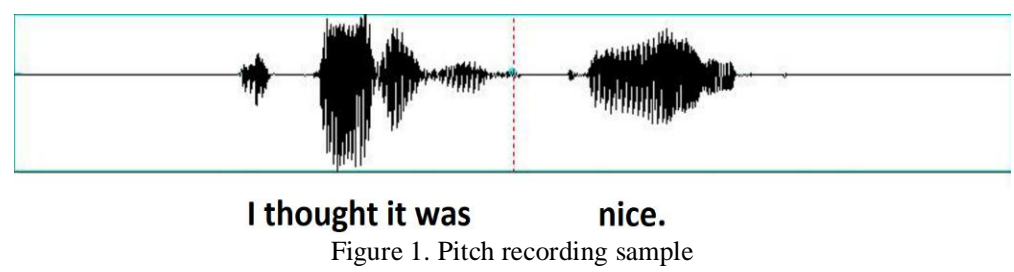

For an adult English language learner this difference between syllable and stress-based languages is of vital importance. This importance is especially pronounced if the learner's first language is rhythmically different from stress-based English or any similar language. In examining the role of stress - "the degree of force used in producing a syllable" (Crystal, 2003) in intelligibility, Field (Field, 2005) asked professional listeners to transcribe recorded material. What is different about this recording is that Field manipulated the variables of word stress and vowel quality. He established that when we erroneously shift word stress to an unstressed syllable, making no changes to vowel quality, the intelligibility of utterances significantly decreases than when only vowel quality is altered. Both native and non-native English speakers gave similar responses in terms of intelligibility of words with misplaced/altered word stress. O'Brien (O'Brien, 2004) reported the results of his research on the significance intonation, rhythm and stress for a native-like German accent. Native speakers of German were tasked with rating American university students reading aloud in German. The research yielded interesting results. Namely, it was found that the native speakers of German shifted their attention more on intonation, rhythm and stress than on individual sounds when rating speech samples as native-like. So, one of the implications of this research for classroom instruction are that both teachers and professors need to spend more time teaching their students/learners the rules for intonation, rhythm and word stress in English, as well as paying attention to individual sounds that may be difficult for the learners in their classes.

\section{Accommodation, Acculturation and Nativisation}

It would seem as though certain learners are quicker to acquire good pronunciation. From our experience, which is probably universal all over the world, even within a relatively uniform classroom, very soon we will start to witness large differences among the pronunciation level of the students. This is why numerous researchers were prompted to study the individual characteristics of learners that are conducive to their successful acquisition of a foreign language. In our short study on pronunciation accuracy, which included 42 students and which is an adapted form of the study conducted by Elliot (Elliot, 1995), we included six statements about pronunciation. Our study utilised five-point Likert scale ranging from never to always and all the questions are related to learners' attitude towards acquiring native or near-native pronunciation as measured by the Pronunciation Attitude Inventory (PAI). 
TABLE 1 STUDENTS' ATTITUDE TOWARDS PRONUNCIATION ${ }^{1}$

\begin{tabular}{|c|c|c|c|c|c|c|c|}
\hline Question & Statistics & Never & $\begin{array}{l}\text { Almost } \\
\text { never }\end{array}$ & Sometimes & $\begin{array}{l}\text { Almost } \\
\text { always }\end{array}$ & Always & Total \\
\hline \multirow{2}{*}{$\begin{array}{l}\text { Proper pronunciation is } \\
\text { vital for me. }\end{array}$} & No. & 2 & 1 & 6 & 20 & 13 & 42 \\
\hline & $\%$ & 4.76 & 2.38 & 14.28 & 42.61 & 30.95 & 100 \\
\hline \multirow{2}{*}{$\begin{array}{l}\text { I want to be as native-like } \\
\text { as possible. }\end{array}$} & No. & 1 & 1 & 2 & 8 & 30 & 42 \\
\hline & $\%$ & 2.38 & 2.38 & 4.76 & 19.04 & 71.42 & 100 \\
\hline \multirow{2}{*}{$\begin{array}{l}\text { I try to emulate native } \\
\text { accent. }\end{array}$} & No. & 2 & 2 & 9 & 11 & 18 & 42 \\
\hline & $\%$ & 4.76 & 4.76 & 21.42 & 26.19 & 42.85 & 100 \\
\hline \multirow{2}{*}{$\begin{array}{l}\text { Good pronunciation is } \\
\text { secondary to grammar and } \\
\text { vocabulary. }\end{array}$} & No. & 19 & 14 & 3 & 3 & 3 & 42 \\
\hline & $\%$ & 45.23 & 33.33 & 7.14 & 7.14 & 7.14 & 100 \\
\hline $\begin{array}{l}\text { I work on improving my } \\
\text { pronunciation }\end{array}$ & $\begin{array}{l}\text { No. } \\
\%\end{array}$ & $\begin{array}{l}4 \\
9.52\end{array}$ & $\begin{array}{l}1 \\
2.38\end{array}$ & $\begin{array}{l}8 \\
19.04\end{array}$ & $\begin{array}{l}16 \\
38.09\end{array}$ & $\begin{array}{l}13 \\
30.95\end{array}$ & $\begin{array}{l}42 \\
100\end{array}$ \\
\hline
\end{tabular}

In Table 1, we can see that students are interested in acquiring good pronunciation. What is "hidden" in this table, but clearly readable from our other data is that younger population is more concerned with good pronunciation, whereas older students are more concerned with functional communication, which does not necessitate native or native-like pronunciation. In other words, if the attitude of students is positive and progressive about improving their pronunciation they really do tended to have better pronunciation of the target allophones (Elliot, 1995). In the same vein, Suter (Suter, 1976) found that students who paid more attention and were more conscious about their pronunciation achieved better results in terms of their pronunciation of English as a Second Language.

In the previous paragraph, we talked about the relation between better pronunciation and students' awareness in terms of how they speak and what they want to achieve. This "active" component which influences one's pronunciation is sometimes accompanied by "more passive" component which has, nevertheless profound impact on one's way of thinking and ultimately on one's pronunciation. Here, we can introduce acculturation model that defines that learners will acquire the target language to the degree that they acculturate (Celce-Murcia, Brinton, \& Goodwin, 1996). As far as Schumann (Schumann, 1986) is concerned, acculturation refers to a learner's openness and willingness to more or less consciously acquire a target culture and his/her desire to be socially integrated in the target culture. In his research from 1986, Schumann examined the level of psychological and social integration of foreign students. He used this level as a predictor of the quantity and quality of English language they acquire and use. Schumann claims that acculturation is an excellent indicator of one's mastery of English and the higher the level of acculturation the better is outcome in terms of somebody's pronunciation. Thus, the reduction of psychological and social distance positively affects one's pronunciation. On the other side, less interaction results in lower acquisition, which has a detrimental effect on one's pronunciation.

Apart from the percentages, showed in Table 1, our research showed that, roughly speaking, students of English, French and other languages at our Faculty, exhibit two types of motivation, which directly affects their pronunciation, among other things. The first type is instrumental motivation, which refers to the desire to learn an L2 in order to accomplish some linguistic goals. This type of students wants to have better pronunciation that may serve them as a way to get better job or something similar. On the other hand, we have integrative motivation and, as the name suggests, students with this type of motivation want to learn about the second language culture. Almost invariably, these students are more likely to socially interact with different native speakers and, thus, are more likely to acquires native or near native accent.

\section{Input and Instruction}

Apart from instructions in terms of what to learn, instructions in terms of how to learn are important as well. Almost invariably, foreign language instructions mainly focus on four areas of interest: speaking, listening, writing and reading. Students learn how to pronounce certain words, but this is often brief and very soon, pronunciation is removed in favour of curriculum elements more useful for preparing a midterm or a final exam. This is why pronunciation is sacrificed since, according to Elliot (Elliot, 1995), teachers have this uncanny tendency to view pronunciation as the least useful of the fundamental language skills and therefore they generally sacrifice pronunciation in order to divert their effort to other "more important" elements of language. Additionally, Pennington (Pennington, 1994) claims that pronunciation, which is typically deemed a linguistic element, rather than a part of conversational fluency, is often regarded with little importance in a communicatively oriented classroom. Another point worth mentioning is that majority of teachers believe adult L2 learners can never attain native or native-like pronunciation, therefore teachers do not have the background or tools to properly teach pronunciation and therefore it is disregarded (Elliot, 1995).

In majority of schools, pronunciation is taught via repetition drills on either a discrete word or phrase level. Nevertheless, these repetition drills are useful for decoding words for the purpose of reading rather than pronunciation. Complementary to repetition drills, we should insist on raising phonemic awareness, which means the ability to hear and pronounce phonemes, without access to print. This is the place where synthetic phonics approach can be used so that learners can be taught to sound and blend the letters in order to pronounce the words. Teachers also shy away from

\footnotetext{
${ }^{1}$ University of Montenegro, Faculty of Philology, $3^{\text {rd }}$ year.
} 
explaining the differences between non-fricative continuants and fricatives, or the subtleties between the trilled or flapped /r/ between Spanish and English (Elliot, 1995). Granted, in order to learn about these subtleties you need to have adequate knowledge, but this kind of information is usually left up to the students. Whether explicit instruction helps these L2 learners is dubious and there are numerous inconsistencies in terms of obtained results. However, majority of research (Suter, 1976), (Elliot, 1995) and (Derwing \& Munro, Second language accent and pronunciation teaching: A research-based approach., 2005) concluded that adults could reach near native fluency, improve their allophonic articulation, achieve better ratings in terms of intelligibility, comprehension and accentedness, if given adequate pronunciation instruction and ample time. One of the origin points of these inconsistencies is created due to different experiment designs. Since pronunciation is very "volatile" in the sense that it is affected by numerous factors, even slight experiment design change can yield vastly different results. Another tendency, based on different research, is that language-learning courses should be based on the suprasegmental features of pronunciation (e.g. intonation, rhythm and stress).

\section{E. Psychology and Personality}

The development of pronunciation is affected by non-linguistic factors. These factors are usually related to individual learning goals, opinion about the target culture, population and language. Usually, these factors are beyond the teacher's control, but the teacher, if s/he is aware of the abovementioned factors can influence and "tweak" the attitude of his/hers students. As it is mentioned in the abstract of this paper, students sometimes feel great discomfort if they have to express themselves in a foreign language. For instance in the Montenegrin language, certain English phonemes such as the voiced dental fricative $/ ð /$ and the voiceless dental fricative $/ \theta /$, when used in our language represent the way a person with a speech sound disorder would speak. These two fricatives are problematic for many young learners to that extent, that they actively avoid using them and transform them, while speaking, into /d/ and / $t /$ respectively. In addition, the two fricatives are perfectly "pronounceable" for almost any language learner from this region, but teachers usually do not pay attention to their pronunciation and $/ \delta /$ and $/ \theta /$ remain fossilised as $/ \mathrm{d} / \mathrm{and} / \mathrm{t} / \mathrm{respectively}$. This observation is corroborated by the research (Burri, Baker, \& Acton, 2016) which showed that a number of learners feel uneasy when trying out new speech rhythm and melody patterns. Others feel stupid and embraced pronouncing "weird" sounds, and with time, they decide it is exercise in futility and that English pronunciation is impossible to acquire. Additionally, it has been shown (Derwing \& Munro, 2015) that one's extraversion and introversion can be beneficial or detrimental to learner's pronunciation. For example, outgoing learners are more likely to find themselves in situations that will elicit some form of communication in a foreign language, which will facilitate their pronunciation. Usually, these students will be more confident and more willing to interact with native speakers.

\section{F. Critical Period Hypothesis}

It is universally accepted that age influences learners' ability to acquire satisfactory pronunciation, but to what extent and how is a matter of debate. According to the "Critical Period Hypothesis" postulated by Lenneberg (Lenneberg, 1967) there is a neurological period, around the age of 12, which is of vital importance in terms of proper pronunciation acquisition. It is of importance that the effects of age on L1 acquisition are apparent across levels of linguistic structure, namely, syntax, phonology, and the lexicon. Snow (Snow, 1987) states there is a period in which people are particularly responsive to linguistic input (namely from birth to the onset of puberty). The same input that during the critical period supports language development is ineffective outside the critical period in producing the same kind of learning. This means the learning that occurs during the critical period is stable and irreversible by subsequent non-critical period learning. The existence of this period and timing of the critical period is controlled by biological maturation. However, (Bialystok, 1997), and (Reed \& Levis, 2015), are not quite convinced that this pre critical period and post critical period delineation is that significant. They do agree that age plays significant role in language learning and the nativeness of pronunciation, but it is far from being the only and the most important or even crucial aspect. It is safe to say that earlier exposure to a foreign language and culture is a good springboard for easier and potentially better pronunciation, but by no means the only factor. Other factors, mentioned in this paper, are also at play. Which one will be the dominant one and which the dormant one, is up to one's individuality. Evidence against the critical period for second language acquisition also can be found in the studies intending to support the hypothesis. Group trends are reported as evidence against the hypothesis. In every case previously cited, counterexamples exist within the data. For some subjects, it appears that significant linguistic sensitivity persists into adulthood. In addition, early exposure does not seem to be sufficient to guarantee success in a second language. (Ioup, Boustagui, Tigi, \& Moselle, 1994) reported on students enrolled in a college (ESL) class. Some of the students in the study had immigrated to the United States as early as 6 years of age. Subjects were given a battery of syntactic and semantic tests that included both productive and receptive tasks. Age of exposure was not a significant determiner of success on these measures. One of the highest performances in the study belonged to a 35-year-old man who had been exposed to English for only 5 years. According to this group of authors (Ioup, Boustagui, Tigi, \& Moselle, 1994) studies on the acquisition of a second language have demonstrated that older learners outperform younger learners if one considers proficiency across many linguistic skills, including pronunciation. Methodological inadequacies within the studies on syntactic development leave the notion of a critical period for syntax untested. Evidence that non-natives can be trained to perform as natives on both productive and receptive tasks weakens support for the notion of a critical period for phonology. Counterexamples to the claim that a 
critical period exists for the acquisition of a first language have been largely anecdotal. The most serious shortcoming for the hypothesis involving first language has been the inability for researchers to posit a plausible neurological cause for the critical period.

\section{G. Negative L1 Transfer}

Since first language is our tool for solving learning and communication problems it is no surprise that the sound pattern of the learner's first language is often transferred into the second language. This transfer may bring about foreign accent. Accents are mainly attributed to a bias in the perception of L2 sounds, stemming from the native (L1) phonology and similar, but not identical sounds (proximate vowels and consonants). According to Flege (Flege, 1995) and his Speech Learning Model (SLM), for instance, similar L2 sounds assimilate perceptually to L1 categories by an equivalence classification mechanism. This mechanism can block L2 category formation, and, in terms of pronunciation, native sounds are often used to reproduce similar L2 sounds. Moreover, Flege postulates that "phonetic categories established in childhood for L1 sounds evolve over the lifespan to reflect the properties of all L1 and L2 phonemes" (p. 239, 1995). On the other hand, dissimilar L2 sounds (i.e., those that are sufficiently phonetically different from the closest native category to be perceived as being different from it) do not perceptually assimilate to L1 categories and abide by dissimilatory drift. This is why Japanese learners have the tendency to assimilate the English /. $/$ / / / / contrast to all-encompassing Japanese $/ \mathrm{r}$, with the English $/ \mathrm{l} /$ being perceptually more similar to the Japanese $/ \mathfrak{r}$ than to the English /I/. In the similar vein, Wenk (Wenk, 1985) who studied non-native speakers' production of English rhythm offers additional support for the negative L1 transfer. He concluded that native language influenced learners' production of English-like stress alternation above the level of word. This means that this negative transfer is a mental and communicative process via which L2 learners develop their inter-language skills by activating and using their previous linguistic knowledge. This previous linguistic knowledge is, arguably, one of the main obstacles to a native or native-like pronunciation.

With regard to the abovementioned, it is possible to draw the conclusion that the native language and its sound system can influence the pronunciation of a target language in the following ways. First, at a phonological level, if a target language sound is missing from the learners' native sound inventory, in these cases, learners may have problems pronouncing or perceiving such target sounds. Second, if phonotactic constraints differ in the learners' mother tongue from the rules present in the target language, they may cause challenges for learners since these rules are language-specific. For example, as opposed to English, certain languages (like Chinese) have no consonant clusters and consonants are always separated by vowels. Thirdly, the rhythm and melody of a language are sometimes invaluable tools in determining the emotional state of interlocutors. They, relatively quickly become hardwired to a person's way of thinking so it is not surprise that learners want to stay inside their pronunciation comfort zone and transfer pronunciation patterns they are familiar with into the target language. All of these elements may be helpful for teachers in terms of their ability to understand all the challenges laid before the learners when learning any language as a second language. Having these elements in mind, may help teachers/instructors/other professionals identify the pronunciation difficulties experienced by non-native speakers.

\section{How to Navigate through the Pronunciation ObStacle Course?}

Pronunciation should be taught within a communicative and meaning-based framework. This means that lectures on English phonology is not sufficient, since pronunciation is not a simple sum of "pieces" of knowledge. The point we wish to convey in this paper is that while knowledge of phonetics and phonology is certainly beneficial, it is by no means sufficient for pronunciation classes. Additionally, we believe it is useful to think of learning to pronounce a new language as a combination of concept formation as well as a physical skill.

\section{A. Communicative Context for Pronunciation}

If the learners are explicitly explained of how pronunciation fits within the general communication framework this may be rather beneficial for them. In this manner, they can gain a clear, practical idea of the nature of pronunciation that should improve their ability to communicate in real life contexts. Furthermore, this framework places its focus on the listener's experience of their speech. In this way, teachers can reduce nervousness and the expectation of failure, which may directly facilitate better "production" in terms of pronunciation. Another point worth mentioning is that learners should know that accents are perfectly nice, it is incomprehensibility that is "bad", not the accent as such. In order to make it easier for learners, we should not make them imitate a native accent but to create intelligible messages, i.e. to make themselves understood. This can be achieved if a foreign language classroom defines errors in terms of intelligibility rather than in terms of non-achievement of a perfect or native model. This also allows teachers to promote successful communication and avoid focussing on deviations from native-like production. In order to improve learners' pronunciation, it is necessary to blur the lines between segmental and suprasegmental aspects of speech, which enables learners to acquire the information structure of speech, which may be exceptionally beneficial in teaching prosody.

\section{B. Learner-centred Approach}


This approach is based on practicing real communicative situations that will be directly useful to them in their real lives. In terms of pronunciation, we are of the opinion that phrases and sentences should be in the focus, but we must not forget about individual sounds and words that should always be discussed within the context of communicative use of language. This means that, ideally, the material learned in class should be perfectly applicable to the learner's real world. However, teachers need to be aware of the fact that learners hear speech very differently and this is why speech and pronunciation should be taught in ways that are logical to the learners. Another point of learner-centred approach is to encourage learners to develop their own skills, which means they should not always rely on the teacher's feedback. In this way, learners are better equipped with tools that will enable them to diagnose and repair pronunciation errors.

\section{CONCLUSION}

Pronunciation is, undoubtedly, one of the most demanding aspects of any language. This skill is arguably one of the most difficult to master and, quite often, the least favourite skill for teachers to address in the classroom. Due to this, we should pay more attention to language pronunciation since there seems to be a strong correlation between good pronunciation and understanding the language-related subtleties. More attention would help teachers and other language-related professionals understand the importance of pronunciation. This would raise awareness and help teachers pay more attention to the students' needs and incorporate pronunciation into their classes and teach both segmental and supra-segmental features, whenever appropriate. Additionally, pronunciation must not be viewed as correct production of isolated sounds, words or phrases. Instead, pronunciation as an integral part of communication should be an essential part of classroom activities. Teachers should start by explaining elements such as sounds, syllables, stress and intonation. Once the students grasp these elements and the way they function, teaches can proceed and build upon this basic awareness. Pronunciation can also be advanced if teachers insist of a relaxed, context-based environment that gradually builds pronunciation skills for both formal and informal purposes. In order to achieve this, we can use different pronunciation-enhancement tools such as: social strategies (interacting with native classmates, asking for clarification, reducing social distance), cognitive strategies (reading in English, taking notes), affective strategies (finding methods to reduce nervousness and anxiety, talking to family or peers about how you feel when you learn a foreign language), metacognitive strategies (contemplating on one's own learning, planning to learn) and compensation strategies (looking for contextual or visual cues, making educated and guesses, using gestures to convey your ideas).

\section{REFERENCES}

[1] Avery, P., \& Ehrlich, S. (1992). Teaching American English Pronunciation. Oxford: Oxford University Press.

[2] Baker, A. (1981). Ship or sheep? An intermediate pronunciation course. Cambridge: Cambridge University Press.

[3] Bialystok, E. (1997). The structure of age: in search of barriers to second language acquisition. Second Language Research, 13(2), 116-137.

[4] Bley-Vroman, R. (1989). What is the logical problem of foreign language learning? (S. M., \& J. Schachter, Eds.) Linguistic perspectives on second language acquisition, 41-68.

[5] Burri, M., Baker, A., \& Acton, W. (2016). Anchoring academic vocabulary with a "hard hitting" haptic pronunciation teaching technique. In T. Jones, Pronunciation in the classroom: The overlooked essential (pp. 17-26). Alexandria: TESOL.

[6] Celce-Murcia, M., Brinton, D., \& Goodwin, J. (1996). Teaching Pronunciation: A reference for teachers of English to speakers of other language. Cambridge: Cambridge University Press.

[7] Crystal, D. (2003). A Dictionary of Linguistics and Phonetics. Oxford: Blackwell.

[8] Davis, C. (1999). Will the use of videos designed for the purpose of teaching English pronunciation improve the learners' production of discrete sounds by at least $80 \%$ over a 12-week period? A Section 353 Project of the Pennsylvania Department of Education, Bureau of Adult Basic and Literacy Education: Pennsylvania Action Research Network.

[9] Derwing, T. M., \& Munro, M. (2015). Pronunciation fundamentals: Evidence-based perspectives for L2 teaching and research. Amsterdam: John Benjamins.

[10] Derwing, T. M., \& Munro, M. J. (2005). Second language accent and pronunciation teaching: A research-based approach. TESOL Quarterly, 39, 379-397.

[11] Elliot, A. R. (1995). Field independence/dependence, hemispheric specialization, and attitude in relation to pronunciation accuracy in Spanish as a foreign language. The Modern Language Journal, 79(3), 356-371.

[12] Field, J. (2005). Intelligibility and the listener: The role of lexical stress. TESOL Quarterly, 39(3), 399-423.

[13] Flege, J. (1995). Two methods for training a novel second-language phonetic contrast. Applied Linguistics, 16, 425-442.

[14] Hinofotis, F., \& Baily, K. (1980). American undergraduate reaction to the communication skills of foreign teaching assistants. On TESOL '80: Building Bridges: Research and Practice in TESL. Alexandria: V.A.

[15] Ioup, G., Boustagui, E., Tigi, M., \& Moselle, M. (1994). Reexamining the critical period hypothesis: a case study of successful adult SLA in a naturalistic environment. Studies in Second Language Acquisition, 16, 73-98.

[16] Lenneberg, E. H. (1967). The geological foundations of language. New York: John Wiley and Sons.

[17] Low, E. L. (2006). A review of recent research on speech rhythm: Some insights for language acquisition, language disorders and language teaching. (R. Hughes, Ed.) Spoken English, TESOL and applied linguistics: Challenges for theory \& practice.

[18] O’Brien, M. G. (2004). Pronunciation matters. Teaching German, 37(1), 1-9.

[19] Pennington, M. (1994). Recent research in L2 phonology: Implications for practice. (J. Morley, Ed.) Pronunciation pedagogy and theory. New views, new directions, 92-108.

[20] Reed, M., \& Levis, J. (2015). Handbook of English pronunciation. West Sussex, England: Wiley-Blackwell. 
[21] Schumann, J. (1986). An Acculturation Model for Second Language Acquisition. Journal of Multilingual and Multicultural Development, 7:5, 379-392.

[22] Snow, C. (1987). Beyond conversation: Second language learners' acquisition of description and explanation. (J. Lantolf, \& A. Labarca, Eds.) Research in second language learning: Focus on the classroom, 3.16.

[23] Suter, R. W. (1976). Predictors of pronunciation accuracy. Language Learning, 26(2), 233-253.

[24] Wenk, B. (1985). Speech Rhythms in Second Language Acquisition. Language and Speech, 28(2), 157-175.

[25] Zielinski, B. (2012). The social impact of pronunciation difficulties: Confidence and willingness to speak. Proceedings of the 3rd Pronunciation in Second Language Learning and Teaching Conference (pp. 18-22). Ames: Iowa State University.

Igor Ivanović graduated from the Faculty of Arts, Nikšić, in 2006. He earned his Master's degree in Translation in 2009 at the Institute of Foreign Languages in Podgorica. In his Master Thesis, he dealt with loanwords and their influence on Montenegrin. In 2014, he finished his PhD studies at the Faculty of Philology in Belgrade and the topic of his dissertation was "Contrastive Analysis of the EU Terminology through the Perspective of Corpus Linguistics".

$\mathrm{He}$ is interested in Corpus Linguistics, Discourse Analysis and CAT Tools. Apart from his teaching obligations at the University of Montenegro, he is very active in written translation pertaining to the following fields: Medicine, Law, Engineering and Economics. In October 2011, he became a Certified Court Interpreter. Apart from his home institution, the Faculty of Philosophy, he is currently engaged at the following faculties: Medicine, Biotechnical, Material Science and Mechanical Engineering where he teaches General English and English for Special Purposes. 